\title{
(2) OPEN ACCESS \\ Methicillin-resistant Staphylococcus aureus (MRSA) panniculitis in a patient undergoing stem cell mobilisation
}

\author{
Ada Pei Yu Ng, ${ }^{1}$ Yen-Lin Chee, ${ }^{2}$ SB Justin Wong, ${ }^{3}$ Wei-Ying Jen ${ }^{2}$
}

\section{${ }^{1}$ Department of Internal Medicine, National University Health System, Singapore ${ }^{2}$ Department of Haematology, National University Cancer Institute Singapore, National University Health System, Singapore \\ ${ }^{3}$ Department of Pathology, National University Health System, Singapore}

\section{Correspondence to}

Dr Ada Pei Yu Ng; ada_ng@nuhs.edu.sg

Accepted 19 January 2021

\section{Check for updates}

(c) BMJ Publishing Group Limited 2021. Re-use permitted under CC BY-NC. No commercial re-use. See rights and permissions. Published by BMJ.

To cite: Ng APY, Chee Y-L, Wong SBJ, et al. BMJ Case Rep 2021;14:e236382. doi:10.1136/bcr-2020236382

\section{SUMMARY}

Methicillin-resistant Staphylococcus aureus (MRSA) can cause a wide range of skin infections, however MRSA panniculitis without bacteremia is a rare manifestation. Here, we report a woman in her 20s with relapsed Hodgkin lymphoma undergoing stem cell mobilisation who presented with bilateral subcutaneous nodules over her shins. Ultrasound scan of one nodule showed non-specific inflammatory changes. Punch biopsy of a nodule showed lobular panniculitis with Gram-positive cocci. Blood cultures were negative but a culture from the biopsy grew MRSA. She was started on doxycycline with improvement in her symptoms. This case serves as a reminder to consider infections as a cause of panniculitis in immunocompromised patients.

\section{BACKGROUND}

Panniculitis usually presents as painful erythematous nodules or plaques and is characterised by inflammation of subcutaneous adipose tissue. Recognition, diagnosis and evaluation is challenging because of its rarity and myriad causes, including infection, malignancy, drugs and inflammatory conditions. Infectious panniculitis can occur primarily after direct inoculation or secondarily from hematogenous spread. ${ }^{1}$ We report a case of methicillin-resistant Staphylococcus aureus (MRSA) panniculitis.

\section{CASE PRESENTATION}

A female in her 20s with relapsed Hodgkin lymphoma (HL) was referred to our centre for autologous stem cell transplantation. She was diagnosed with stage $2 \mathrm{HL}$ in 2016 and underwent chemoradiotherapy, attaining complete remission. She relapsed in 2019 with a recurrent mediastinal mass and widespread lymphadenopathy. She underwent salvage chemotherapy with bendamustine and brentuximab (BB), which was uneventful except for a grade 1 cutaneous adverse drug reaction (CADR) to BB affecting 5\% of her body surface area. This resolved with topical steroids and antihistamines. She had no other significant medical or surgical history. Medication on admission for stem cell harvesting included chlorpheniramine $4 \mathrm{mg}$ two times per day, mometasone $0.1 \%$ lotion two times per day for her previous CADR and acyclovir $400 \mathrm{mg}$ two times per day for prophylaxis against herpes zoster.

The patient went on to receive mobilisation chemotherapy with ifosfamide, carboplatin and etoposide. Pegfilgrastim was administered on days 5 and 11 . On day 11, she was admitted with a fever of $38.3^{\circ} \mathrm{C}$ and pain in her legs. Examination revealed bilateral scattered tender, indurated subcutaneous nodules over her shins with mild overlying erythema, approximately $3-5 \mathrm{~cm}$ in diameter (figure 1). There was a residual dry scaly excoriated hyperpigmented rash from the previous CADR.

\section{INVESTIGATIONS}

Investigations on admission showed a white cell count of $0.79 \times 10^{9} / \mathrm{L}$, with neutrophils $0.56 \times 10^{9} / \mathrm{L}$. Following admission, she was started on daily filgrastim due to her neutropaenia and low CD34+ count, which precluded successful mobilisation. C-reactive protein (CRP) was elevated at 74, and procalcitonin was 0.18 . Blood cultures and a blood fungal culture were negative. An ultrasound scan of the leg nodule showed vague increased echogenicity and increased vascularity in the subcutaneous tissue with no evidence of abscess formation. A punch biopsy of the nodule confirmed lobular panniculitis with an inflammatory cell infiltrate composed of numerous neutrophils, mixed with lymphocytes,

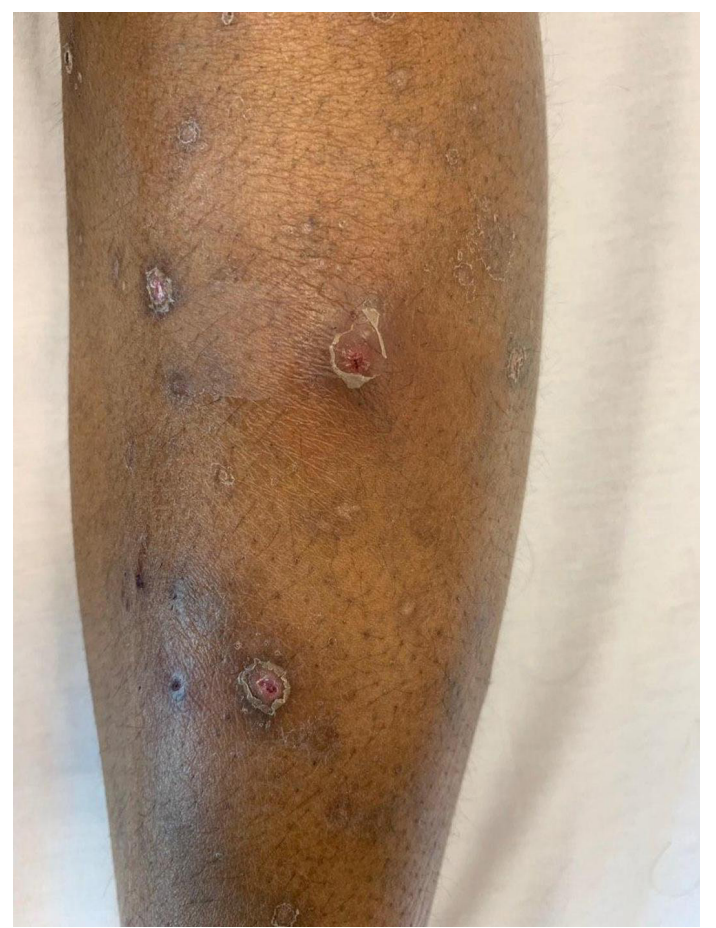

Figure 1 Photo of subcutaneous nodule on the lower limb. 


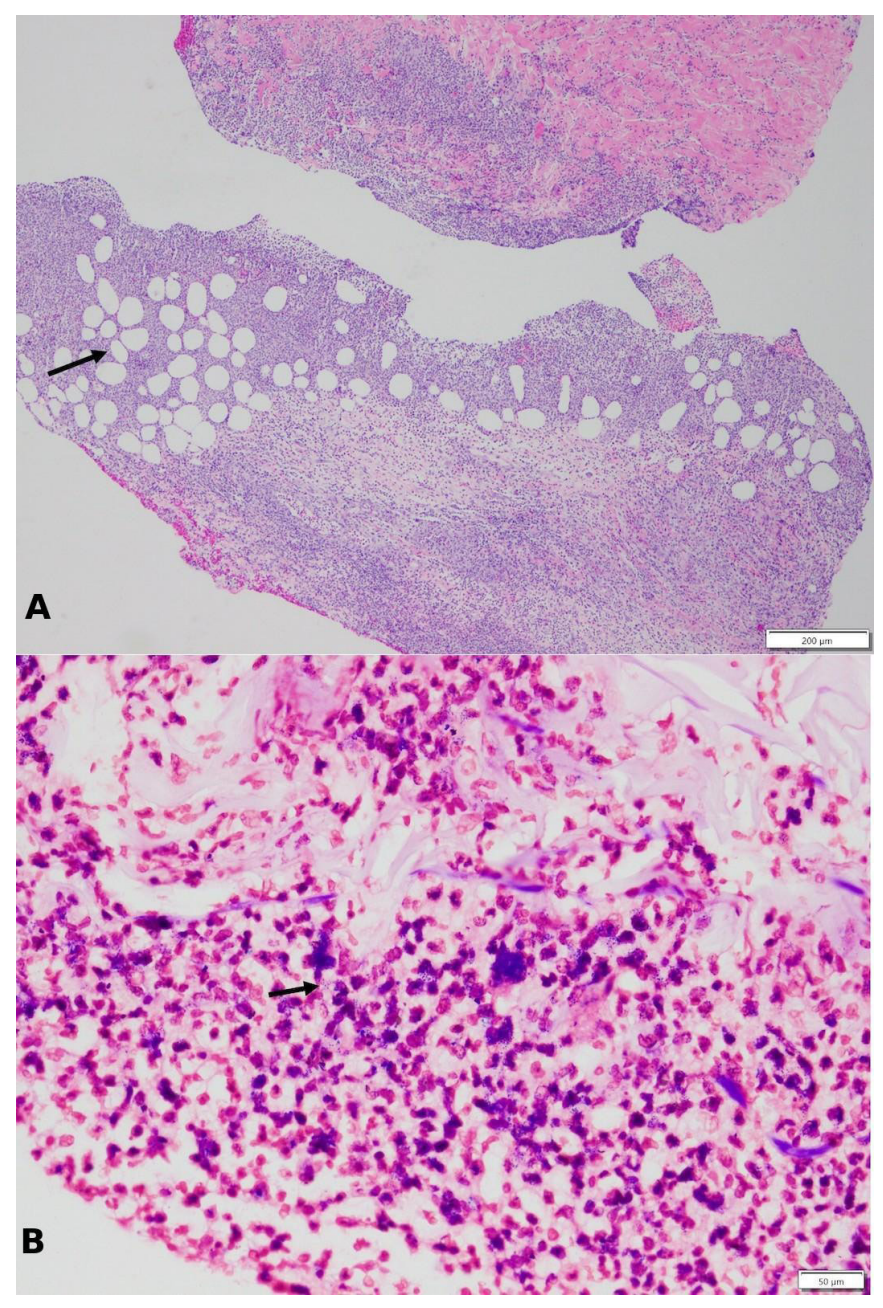

Figure 2 (A) Histology slide showing lobular panniculitis with an inflammatory cell infiltrate composed of numerous neutrophils, mixed with lymphocytes, eosinophils, histiocytes and occasional multinucleated giant cells. (B) Histology slide showing Gram-positive cocci.

eosinophils, histiocytes and occasional multinucleated giant cells (figure 2A). Granulomas were not observed. No features of vasculitis were identified. Gram-positive cocci were present in the dermis and subcutis (figure 2B). No fungal organisms or acid-fast bacilli were seen on Grocott's methenamine silver or Ziehl-Neelsen stains. Culture from the punch biopsy grew MRSA. Her antinuclear antibody titre was negative at $<1: 80$. A tuberculosis quantiferon test was negative, and a chest radiograph was normal.

\section{TREATMENT}

A diagnosis of infective panniculitis secondary to MRSA was made. She was started on doxycycline with resolution of her fever and nodules. Her filgrastim injections were continued till neutrophil recovery.

\section{OUTCOME AND FOLLOW-UP}

The patient unfortunately failed to mobilise peripheral blood stem cells but went on to have a successful bone marrow harvest with no evidence of microbial contamination of her cyropreserved stem cells. Her lower limb subcutaneous nodules also resolved completely without scarring nor atrophy following treatment with doxycycline.

\section{DISCUSSION}

Panniculitis can be classified as septal or lobular, with or without vasculitis. Histologically, infectious panniculitis presents as a neutrophilic predominant mixed inflammatory infiltrate with a lobular pattern of inflammation. ${ }^{2}$ Infective panniculitis can be caused by bacterial, mycobacterial, fungal, protozoal or viral infections. $S$. aureus is a skin commensal commonly responsible for primary cutaneous lesions such as folliculitis, carbuncles or cellulitis. Deeper pathology such as abscesses or rarely, panniculitis may result from haematogenous spread in bacteraemic patients, ${ }^{3}$ or following inoculation from primary superficial lesions. In our patient, repeated blood cultures were negative for $S$. aureus. Given this, we hypothesise that her prior CADR to BB chemotherapy resulted in weakened skin integrity, superficial inoculation and subsequent deep tissue infection which flared opportunistically when she was neutropaenic. To our knowledge, MRSA-induced panniculitis without bacteremia is rare. However, there have been a few reports of this phenomenon with Pseudomonas aeruginosa. ${ }^{4}$

We initially considered filgrastim-induced panniculitis as a differential. Filgrastim has been associated with several cutaneous reactions such as Sweet's syndrome, pyoderma gangrenosum and vasculitis. A few cases have been reported in association with pegfilgrastim. ${ }^{6}$ Possible hypotheses include secondary cytokine production after filgrastim administration and neutrophil activation. ${ }^{7}$ In our patient, the temporal relationship between administration of pegfilgastrim and her symptoms initially led us to suspect pegfilgrastim as the cause of her panniculitis. However given her positive biopsy culture for MRSA, the presence of Gram-positive cocci in her dermis and subdermal layer, and clinical response to doxycycline despite being continued on filgrastim, we deemed this unlikely.

The site of the lesions, clinical context of HL and neutrophilrich inflammatory infiltrate also raise the possibility of erythema nodosum. Erythema nodosum is usually idiopathic, but has also been associated with infection, drug, inflammatory condition or malignancy. ${ }^{8}$ Although this is classically a septal panniculitis, ${ }^{9}$ there can be histological overlap in some cases. ${ }^{10}$ Our patient's biopsy was in keeping with that of a lobular panniculitis. Her culture was positive for MRSA which is not a typical infection associated with erythema nodosum. In view of this and her quick response to doxycycline, we concluded erythema nodosum to be less probable.

The possibility of bacterial contamination during the biopsy procedure was also considered. MRSA is endemic in healthcare facilities, ${ }^{11}$ and patients who are colonised with MRSA may contaminate surrounding environmental surfaces. ${ }^{12}$ Our institution carries out active surveillance to identify MRSAcolonised patients. Our patient's MRSA swabs (nasal, axilla and groin) were persistently negative. In addition, the procedure was done under aseptic technique, MRSA was cultured and demonstrated in histology specimens, and she improved following the

\section{Learning points}

- Infectious panniculitis due to Staphylococcus aureus in the absence of bacteraemia is extremely rare.

- Careful workup including biopsy and culture is important to allow correct identification of aetiology and appropriate management.

- Appropriate diagnosis allowed continued filgrastim injections so that her time-sensitive stem cell harvest could proceed. 
institution of antimicrobial therapy. In light of this, bacterial contamination was considered unlikely.

Contributors APYN drafted the manuscript. Y-LC and W-YJ reviewed and revised the manuscript. SBJW analysed the histology specimen.

Funding The authors have not declared a specific grant for this research from any funding agency in the public, commercial or not-for-profit sectors.

Competing interests None declared.

Patient consent for publication Obtained.

Provenance and peer review Not commissioned; externally peer reviewed.

Open access This is an open access article distributed in accordance with the Creative Commons Attribution Non Commercial (CC BY-NC 4.0) license, which permits others to distribute, remix, adapt, build upon this work non-commercially, and license their derivative works on different terms, provided the original work is properly cited and the use is non-commercial. See: http://creativecommons.org/ licenses/by-nc/4.0/.

\section{REFERENCES}

1 Delgado-Jimenez Y, Fraga J, García-Díez A. Infective panniculitis. Dermatol Clin 2008:26:471-80.

2 Chan MP. Neutrophilic panniculitis: algorithmic approach to a heterogeneous group of disorders. Arch Pathol Lab Med 2014;138:1337-43.
3 Young TK, Gutierrez D, Meehan SA, et al. Neutrophilic panniculitis arising from hematogenous spread of methicillin-resistant Staphylococcus aureus. Pediatr Dermatol 2020;37:531-3.

4 Picard D, de Quatrebarbes J, Gueit I, et al. Atypical nodular panniculitis. Int J Infect Dis 2011;15:e289-90.

5 Roriz M, Maruani A, Le Bidre E, et al. Locoregional multiple nodular panniculitis induced by Pseudomonas aeruginosa without septicemia: three cases and focus on predisposing factors. JAMA Dermatol 2014;150:628-32.

6 Ichiki T, Sugita K, Goto H, et al. Localized pegfilgrastim-induced neutrophilic dermatosis with tissue G-CSF expression: a Mimicker of sweet's syndrome. Acta Derm Venereol 2019:99:685-6.

7 Spiekermann K, Roesler J, Emmendoerffer A, et al. Functional features of neutrophils induced by G-CSF and GM-CSF treatment: differential effects and clinical implications. Leukemia 1997;11:466-78.

8 Schwartz RA, Nervi SJ. Erythema nodosum: a sign of systemic disease. Am Fam Physician 2007;75:695.

9 Requena L, Yus ES, Part P I. Mostly septal panniculitis. J Am Acad Dermatol 2001;45:163-83.

10 Thurber S, Kohler S. Histopathologic spectrum of erythema nodosum. J Cutan Pathol 2006;33:18-26.

11 Hsu L-Y, Tan T-Y, Jureen R, et al. Antimicrobial drug resistance in Singapore hospitals. Emerg Infect Dis 2007;13:1944-7.

12 Oie S, Suenaga S, Sawa A, et al. Association between isolation sites of methicillinresistant Staphylococcus aureus (MRSA) in patients with MRSA-positive body sites and MRSA contamination in their surrounding environmental surfaces. Jpn J Infect Dis 2007;60:367-9.

Copyright 2021 BMJ Publishing Group. All rights reserved. For permission to reuse any of this content visit https://www.bmj.com/company/products-services/rights-and-licensing/permissions/

BMJ Case Report Fellows may re-use this article for personal use and teaching without any further permission.

Become a Fellow of BMJ Case Reports today and you can:

Submit as many cases as you like

- Enjoy fast sympathetic peer review and rapid publication of accepted articles

- Access all the published articles

Re-use any of the published material for personal use and teaching without further permission

Customer Service

If you have any further queries about your subscription, please contact our customer services team on +44 (0) 2071111105 or via email at support@bmj.com.

Visit casereports.bmj.com for more articles like this and to become a Fellow 